\title{
The Journal and its First Decade
}

\author{
Eelco F. M. Wijdicks
}

Published online: 31 December 2013

(C) Springer Science+Business Media New York 2013

First, there was no interest. No major publisher "believed" in a Neurocritical Care journal-too specialized, too much competition, too expensive to produce and no official Society. Where would the articles come from? It was tempting to think that the journal could only emerge after sifting articles away from other journals.

At a scientific meeting and by mere serendipity I met a representative of Humana Press together with Stephan Mayer and Gene Sung (who became associate editors). It did not take long for Humana Press to step in and now 10 years later, we believe we have a "respectful, resourceful, and recognizable journal" [1]. Our obstinacy paid off and now 20 volumes, 65 issues, and 1,300 articles later, we mark the first 10 years of the journal.

At the beginning of each new year, I have discussed important aspects of the journal's mission, and it is not my intent to overwhelm the readership with a comprehensive reminiscence or some other blaring statistic because none of them adequately judge a journal. Not even a bibliometric statistic such as the impact factor (3.08 and increasing) and perhaps not even a webometric such as the number of downloads (over 200,000 annually and counting) may tell us how a journal is doing. Our aim has always been to be a practical, attractive, and newsworthy journal. Our metric is not a complex statistic - nothing measures what we want it to measure-but whether the study results are interesting and reviews are engrossing.

Many read the journal on line (and very soon using our app) but others still like the physicality of a journal. When an issue arrives we hope it stops you in your tracks and you

E. F. M. Wijdicks ( $\square)$

Division of Critical Care Neurology, Mayo Clinic, Rochester, MN 55905, USA

e-mail:wijde@mayo.edu do not put it (with its cellophane cover intact) on that "never to be read" pile in the corner of your office. One of my fellows was "deeply into" the journal and did not hear his pager go off. That to me is more important than any other trend, figure, or percentage.

Over the last 10 years, there has been a substantial increase in submissions-we now handle about 500 manuscripts a year. Most of these are from the US, but there is a growing number from Canada, Germany, and other European countries. This increases our global appeal, even in countries where Neurocritical Care (with a big N) is not yet an established specialty (remember the subtitle of our journal is "A Journal of Acute and Emergency Care").

I love this job but I am also the rejector-in-chief. The acceptance rate has significantly decreased and is now at $35 \%$. That is comparatively low for a subspecialty journal, but our reviewers are critical and involved. Some papers do not belong in our journal. Some papers ruminate the wellknown facts. Some papers come to us because every other journal has rejected them. Rejection is painful, trying to appeal a decision is even more painful for the author and also for the editor-in-chief.

I have tried not to flood the journal with manuscripts coming out of our institution - as so many other editors do-and I counted about 60 over 10 years-a very small fraction of the total published papers. Still this is the journal where neurointensivists should go and not after a frustrating run through other Neurology, Anesthesia, or Critical Care journals and we also like to publish in here. I thank the associate editors who handled our papers and papers where I conflicted with the data or concepts.

I come across good writers and bad writers-good reviewers and bad reviewers-good sports and irritated authors but in the end I see an enthusiastic group of academicians. 


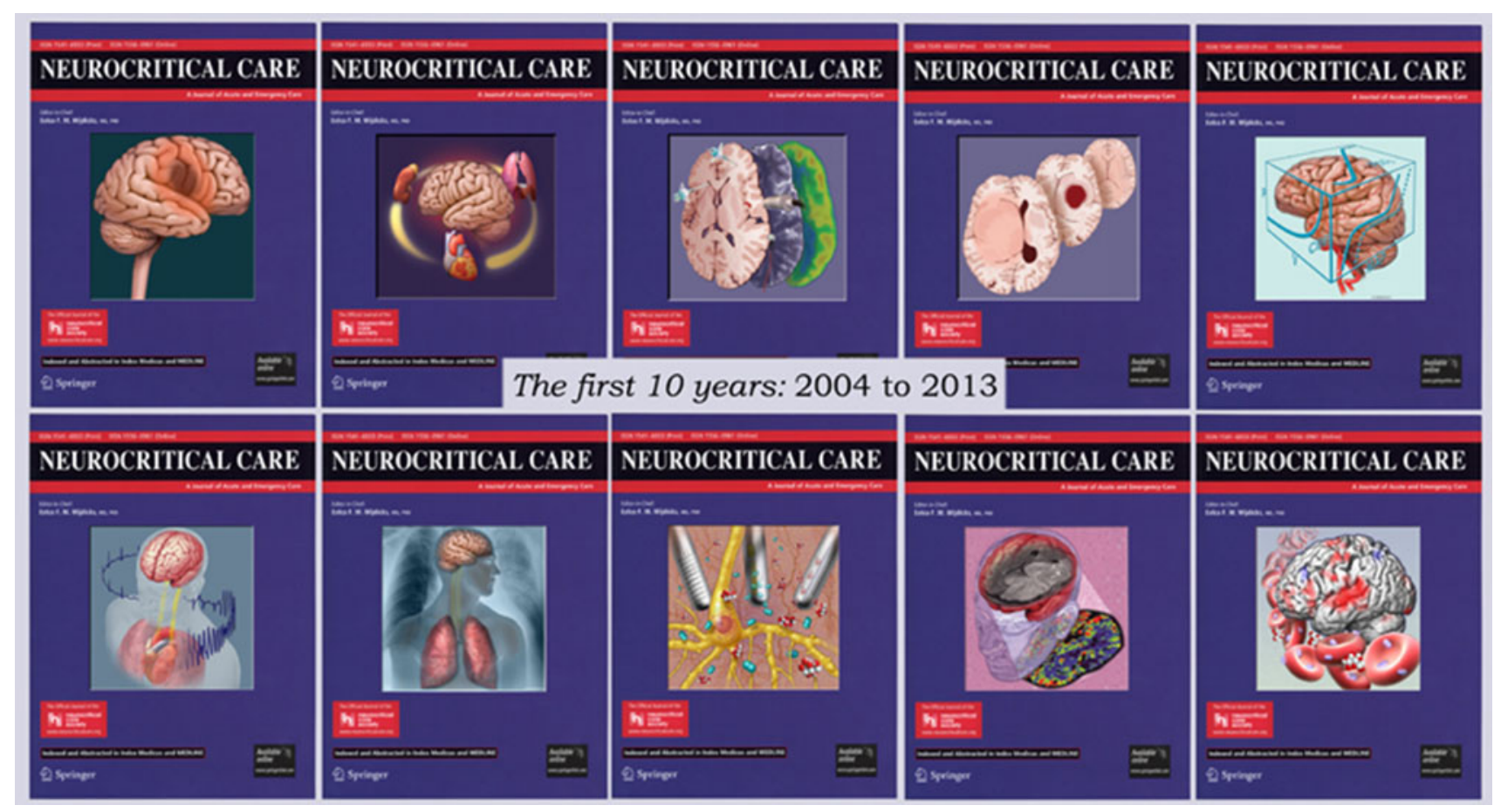

Fig. 1 Collage of Neurocritical Care covers

Table 1 Support staff of Neurocritical Care

\begin{tabular}{ll}
\hline Years active & Springer team \\
\hline 2004-present & Richard Lansing, Editorial Director \\
2011-present & Rebekah Amos, Editor \\
2012-present & James Langlois, Production Editor \\
2004-present & Annette Triner, Production Manager \\
2004-present & Henry Krell, Vice President \\
2006-2012 & Benjamin Ellis, Production Editor \\
2010-present & Verena Diem, Product Manager \\
2010-present & Srilakshmi Patrudu, JEO Assistant \\
\hline
\end{tabular}

I think our journal looks good. I maybe the last romantic but I think the journal should have an attractive cover; and it is, therefore, appropriate to sincerely thank medical illustrator David Factor (Fig. 1), who has been responsible for all the wonderful drawings and his accomplishments are unparalleled. (He also made the new cover illustration that will appear in the upcoming years.) I am thankful for Springer-who incorporated Humana Press-to support our journal. There is a hard-working staff that helps in creating an online and print issue-I lean heavily on them and I am grateful for their commitment (Table 1).

Virtually all editorial boards switch after 10 years, but the Neurocritical Care Society has decided I will stay on for a few more years. We have a strong editorial board and
I want to keep it that way. We tried to keep a link with the Neurosciences and tried to expand this section without needlessly proliferating into a semi-neuroscience journal. The expert judgment of the basic science editor David Warner should be particularly recognized. I will continue to try to do something new each year and will introduce new topic headings. We will gradually increase the number of issues and try to transition to monthly depending on the paper flow. (I do not know if anyone who matters thinks that that is important because articles are on line soon after acceptance.) The journal's main duty has been to prove that our specialty has a strong academic underpinning and solid work can have a home. Most importantly, I have the privilege to see in front of my eyes the development of an important specialty in neurology and critical care-a specialty that is committed to acute and emergency care and that is advancing with new science, new concepts, and new insights. We are pleased that the Neurocritical Care Society has embraced this journal. But in the end, it is the observant practitioner and the scientific author who deserve a tribute.

\section{Reference}

1. Wijdicks EFM. A new journal, a new step, a new energy. Neurocrit Care. 2004;1:1-2. 